\title{
The mammalian PYHIN gene family: Phylogeny, evolution and expression
}

\author{
Jasmyn A Cridland ${ }^{1}$, Eva Z Curley ${ }^{1}$, Michelle N Wykes ${ }^{2}$, Kate Schroder ${ }^{3}$, Matthew J Sweet ${ }^{3}$, Tara L Roberts ${ }^{2}$, \\ Mark A Ragan ${ }^{3,4}$, Karin S Kassahn ${ }^{3,4,5}$ and Katryn J Stacey ${ }^{1,3^{*}}$
}

\begin{abstract}
Background: Proteins of the mammalian PYHIN (IFI200/HIN-200) family are involved in defence against infection through recognition of foreign DNA. The family member absent in melanoma 2 (AIM2) binds cytosolic DNA via its HIN domain and initiates inflammasome formation via its pyrin domain. AIM2 lies within a cluster of related genes, many of which are uncharacterised in mouse. To better understand the evolution, orthology and function of these genes, we have documented the range of PYHIN genes present in representative mammalian species, and undertaken phylogenetic and expression analyses.

Results: No PYHIN genes are evident in non-mammals or monotremes, with a single member found in each of three marsupial genomes. Placental mammals show variable family expansions, from one gene in cow to four in human and 14 in mouse. A single HIN domain appears to have evolved in the common ancestor of marsupials and placental mammals, and duplicated to give rise to three distinct forms (HIN-A, - B and -C) in the placental mammal ancestor. Phylogenetic analyses showed that AIM2 HIN-C and pyrin domains clearly diverge from the rest of the family, and it is the only PYHIN protein with orthology across many species. Interestingly, although AIM2 is important in defence against some bacteria and viruses in mice, AIM2 is a pseudogene in cow, sheep, llama, dolphin, dog and elephant. The other 13 mouse genes have arisen by duplication and rearrangement within the lineage, which has allowed some diversification in expression patterns.

Conclusions: The role of AIM2 in forming the inflammasome is relatively well understood, but molecular interactions of other PYHIN proteins involved in defence against foreign DNA remain to be defined. The non-AIM2 PYHIN protein sequences are very distinct from AIM2, suggesting they vary in effector mechanism in response to foreign DNA, and may bind different DNA structures. The PYHIN family has highly varied gene composition between mammalian species due to lineage-specific duplication and loss, which probably indicates different adaptations for fighting infectious disease. Non-genomic DNA can indicate infection, or a mutagenic threat. We hypothesise that defence of the genome against endogenous retroelements has been an additional evolutionary driver for PYHIN proteins.
\end{abstract}

Keywords: PYHIN, HIN-200, cytosolic DNA, ALR, IFI16, AIM2

\section{Background}

Members of the PYHIN protein family have recently come to prominence as receptors mediating the detection of foreign DNA and initiating innate immune responses. Absent in melanoma 2 (AIM2) binds DNA in the cytosol of macrophages and mediates activation of

\footnotetext{
* Correspondence: katryn.stacey@uq.edu.au

${ }^{1}$ The University of Queensland, School of Chemistry and Molecular Biosciences, Brisbane, Qld 4072, Australia

${ }^{3}$ The University of Queensland, Brisbane, Qld 4072, Australia

Full list of author information is available at the end of the article
}

the inflammasome pathway [1-4]. A second family member, p202, binds to cytosolic DNA and antagonises this pathway [4]. The inflammasome is a protein complex initiating activation of the protease precursor procaspase 1 . Active caspase 1 cleaves proIL- $1 \beta$ and proIL-18 prior to their secretion as active inflammatory cytokines, and also leads to rapid lytic cell death termed "pyroptosis" [5]. AIM2-mediated responses are elicited by viruses such as mouse cytomegalovirus (MCMV) and vaccinia, the cytosolic bacteria Francisella tularensis and Listeria monocytogenes, and even extracellular bacteria such as

\section{Biomed Central}


Streptococcus pneumoniae [6-11]. AIM2 was necessary for effective control of Francisella tularensis and MCMV infection of mice $[6,7,11]$.

Another PYHIN family member, human IFI16, was shown to mediate inflammasome responses to Kaposi's sarcoma virus DNA in the nucleus [12]. Infection led to increased nuclear colocalisation of IFI16 with ASC, followed by emigration of both factors into the perinuclear region. IFI16 but not AIM2 knockdown decreased procaspase- 1 cleavage in response to viral infection. On the other hand, IFI16 and mouse PYHIN protein p204 were found to play a role in the recognition of foreign DNA leading to induction of interferon- $\beta$ (IFN- $\beta$ ), which is a pathway distinct from the inflammasome [13]. Induction of IFN- $\beta$ by cytosolic DNA requires the adapter protein STING (stimulator of interferon genes), and subsequent activation of TANK-binding kinase 1 (TBK1) leading to phosphorylation and nuclear translocation of the transcription factor interferon regulatory factor-3 (IRF-3) [14-18]. IFI16 is not the only contender for such a role in DNA recognition, as recent work suggests that the unrelated helicase protein DDX41 is the DNAbinding protein primarily required for the early induction of signalling leading to IFN- $\beta$ production whilst IFI16-mediated responses to DNA may prolong the induction of IFN- $\beta$ later in the response [19]. Both IFI16 and DDX41 were reported to bind to STING $[13,19]$. Overall, study of the PYHIN gene family has been hampered by the complexity of the family in mouse, and a lack of understanding of orthology between mouse and human genes.

The PYHIN genes were identified as a cluster on mouse and human chromosome 1 and were named mouse Ifi200 ("interferon inducible") [20,21] and human HIN-200 ("hematopoietic, interferon-inducible nuclear proteins with a 200 amino acid repeat") [22]. They have more recently been annotated as the "PYHIN" family, acknowledging the defining features of an N-terminal pyrin domain and C-terminal HIN domain. There are four human PYHIN proteins: IFI16 (interferon inducible protein 16) [23], MNDA (myeloid nuclear differentiation antigen) [24], AIM2 [25] and IFIX (interferon inducible protein X) [26]. Publications have so far detailed seven mouse proteins p202(a/b), p203, p204, p205, p206, Aim2/p210, and Mndal (MNDA-like) as well as a number of predicted proteins [22,27-30]. Family members are predominantly nuclear proteins, some with defined nuclear localisation signals [22]. There is potential for regulated localisation, since acetylation of the nuclear localisation signal of IFI16 led to its cytosolic accumulation [31]. Some family members have characterised nuclear export sequences [32], suggesting they may shuttle in and out of the nucleus. In contrast, p202 and AIM2 lack nuclear localisation signals and reside in the cytoplasm of untreated cells $[2,4]$, consistent with the role of AIM2 and p202 in the recognition of cytosolic DNA. p206 is also reported to have cytoplasmic location [27].

Prior to the finding that members of the family function in pathogen recognition, publications focused on roles in cell growth and cell cycle control, tumour suppression, apoptosis, DNA damage response, senescence, muscle and myeloid differentiation and autoimmunity [33-38]. These functions are comprehensively reviewed elsewhere [22,39-42]. There is as yet limited insight into the specific molecular roles of the proteins in these diverse functions. Various family members have been found to bind tumour suppressors such as p53, BRCA1 (breast cancer 1, early onset) and retinoblastoma protein [34,43-45], supportive of roles in cell cycle regulation, DNA repair and apoptosis. Interactions with a range of transcription factors and signalling molecules are also reported [46-50]. The novel roles being uncovered for PYHIN proteins in host defence now provide relevance for the long-established interferon-inducibility of these genes. Consistent with viral need to evade detection, several viral proteins are characterised to bind PYHIN family members [51-53].

The PYHIN proteins are defined by the possession of one or two 200-amino acid HIN domains at the C terminus, and a pyrin domain at the $\mathrm{N}$ terminus $[22,40]$. The roles of the HIN and pyrin domains are well established for AIM2-mediated inflammasome responses $[1,2]$. AIM2 recognises DNA via its HIN domain, and then recruits the inflammasome adapter protein ASC (apoptosis-associated speck-like protein containing a CARD) via homotypic interaction of pyrin domains. ASC itself recruits procaspase 1 via its caspase recruitment domain (CARD), resulting in intermolecular cleavage to give active caspase 1 . The pyrin domain of AIM2 can therefore be considered the effector domain eliciting inflammasome formation. Pyrin domains (also known as PYD, PAAD or DAPIN) are also found in other proteins involved in inflammasome formation, such as NOD-like receptors. They are part of the death domain superfamily which also includes the death domain, death effector domain, and CARD [54]. Death domains form six-helix bundles and are frequently involved in recruitment of proteins in apoptotic and inflammatory responses through homotypic interactions.

The HIN domain is unique to the PYHIN family, and three distinct sequence classes, $\mathrm{HIN}-\mathrm{A},-\mathrm{B}$, and $-\mathrm{C}$, have been defined [22]. The HIN domain was predicted to combine two oligonucleotide/oligosaccharide binding (OB)-folds [55]. OB-folds are five-stranded $\beta$-barrel structures found in a number of single stranded DNA (ssDNA)-binding proteins such as replication protein A and breast cancer 2, early onset (BRCA2). The OB-fold 
prediction is now supported by the crystal structures of the HIN domains of IFI16 and AIM2 [56,57]. The structure of double stranded (ds) DNA-bound proteins [56] showed that interaction between the HIN domains and DNA was primarily by electrostatic interaction with the sugar-phosphate backbone, explaining the DNA sequence-independent responses to cytosolic DNA. This work also suggested that in the absence of DNA, the pyrin domain is bound to the HIN domain in an autoinhibited state. Unterholzner et al. showed that the tandem HIN domains of IFI16 were more effective in DNA binding than its single HIN-B domain, with the HIN-A domain alone being ineffective [13]. Interestingly, recent work showed that IFI16 had a preference for binding cruciform structure DNA [58]. Native mouse p202, which also has two HIN domains, strictly bound to dsDNA and not ssDNA [4], and biological responses mediated via AIM2 are dependent on dsDNA, and are not elicited by ssDNA [4]. Beyond this, whether the HIN domains of different PYHIN family members have any specificity for particular DNA sequences or structures remains to be established.

The presence of four PYHIN family members in human has been known for a number of years, but the number of predicted mouse genes has increased with each new release of the mouse genome. In this paper, we describe the mouse, human and rat gene loci and proteins, address the issue of orthology between mouse and human genes and expression of the many mouse genes, and examine the evolution of the gene family within mammals. This provides a picture of a rapidly evolving locus with vastly different gene repertoires in different mammalian species and even within mouse strains. Phylogenetic analysis shows a clear distinction between AIM2 and other family members, suggesting divergence in function. Surprisingly, given the important role for AIM2 in host defence in mouse, AIM2 appears only as a pseudogene in a number of different lineages, and appears to have been lost from genomes on several independent occasions during evolution.

\section{Results and Discussion}

\section{The PYHIN Gene Locus in Mouse}

The PYHIN gene cluster is found in a syntenic region in many mammals, located between the Cell Adhesion Molecule 3 (CADM3) gene and a collection of olfactory receptors and spectrin alpha chain (SPTA1), on chromosome 1q band H3 in mouse, 1q23 in human, and 13q24 in rat (Figure 1). On the basis of predicted genes and cDNA sequences, we PCR-cloned the open reading frames of 12 factors mapping to the locus from C57BL/6 splenic cDNA (Ifi203-205, 207-214) (Table 1, Figure 1) or cDNA from RAW264 cell line (Ifi202) and obtained cDNA for Ifi206 from Ricky Johnstone (Peter
MacCallum Cancer Centre, Melbourne). A fourteenth predicted gene [MGI: Gm16340] can be discerned but there is only sparse EST evidence supporting its expression, compared with other genes. It encodes an intact open reading frame, and differs from Ifi203 in only 25 amino acids out of 410 , hence we have here termed it Ifi203'. The gene denoted here Ifi207, identified by Ludlow et al. [22] appears identical with Ifi201, for which a partial genomic DNA sequence had been published [21]. Although our cloned cDNA for Ifi208 encodes a protein without a HIN domain, there is a HIN domain encoded by DNA immediately downstream of Ifi208 (Figure 1), which is represented in EST databases. Thus a HIN-containing splice variant of Ifi208 may exist.

\section{Divergence of the locus between mouse strains}

The PYHIN gene locus is divergent in different mouse strains. The region encoding Mndal/Ifi212 is absent in a number of related mouse strains including $\mathrm{DBA} / 2 \mathrm{~J}$, $\mathrm{AKR} / \mathrm{N}$, and NZB/BINJ [28]. Part of Ifi203 is also missing in DBA [28], explaining the lack of Ifi203 mRNA in that strain [59]. Zhang et al. [28] presented an arrangement of genes in the locus generated from two overlapping BAC sequences, one from $\mathrm{C} 57 \mathrm{BL} / 6$ and one from 129X1/SvJ. This presents a model not consistent with the current C57BL/6 genome, and suggests that the 129 strain may be missing the genes Ifi211 and Ifi203 which lie between Mndal/Ifi212 and Ifi202 in C57BL/6 (Figure 1). In contradiction to this, an earlier map of the 129 strain mouse locus showed two extra duplications of Ifi203 [20], one of which may be Ifi203' (Gm16340). In addition, there are two Ifi202 genes and a pseudogene in the 129 mouse genome, designated Ifi202a, $b$ and $c[20,60]$, but only one Ifi202 gene in C57BL/6 (Figure 1), which has a number of minor sequence variations from the published Ifi202a and $b$ [60]. Thus it seems that in the mouse lineage, the PYHIN locus has been subject to frequent amplification and rearrangement.

\section{Human and rat PYHIN loci}

The human locus is simpler, with 4 identified genes (AIM2, IFI16, IFIX, MNDA, Figure 1). The human AIM2 gene, like mouse $A i m 2$, lies in the reverse orientation to other genes at one end of the gene cluster near the $C A D M 3$ gene. Interestingly, the human locus may also be prone to duplications, as a recent paper reports copynumber variation, including within the IFI16 gene, in the human population [61]. The rat genome is incomplete, with gaps remaining within the locus. There are currently four identifiable genes with both pyrin and HIN domains (Aim2 and Rhin2-4) and an isolated pyrin domain (Rhin5) (Figure 1). EST databases support the expression of all the rat genes except Rhin5. 


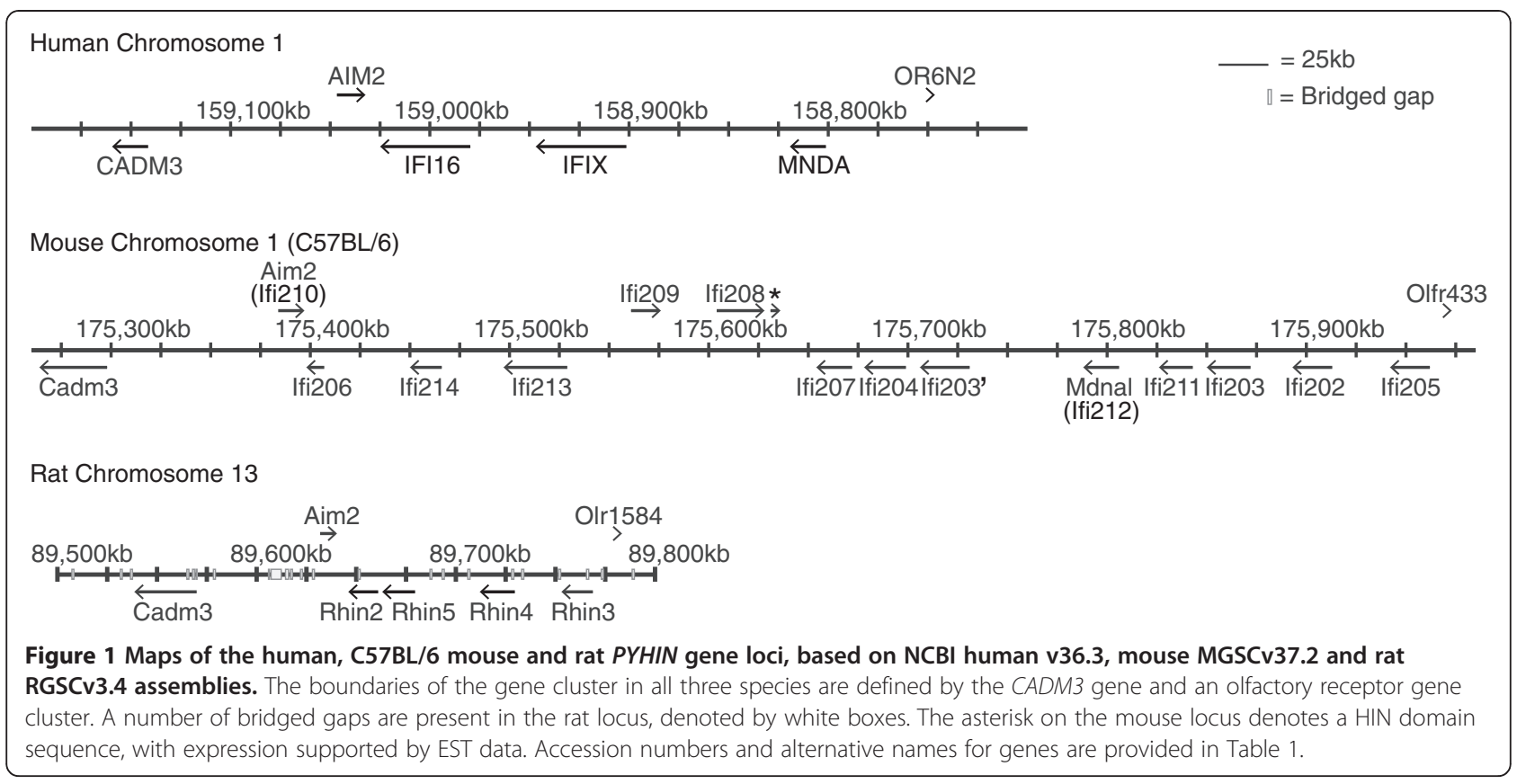

Table 1 Mouse, human and rat PYHIN gene accession numbers and nomenclature. Mouse sequences are from C57BL/6

\begin{tabular}{|c|c|c|c|c|c|}
\hline Species & Name & Gene ID & Gene Symbol & Genbank Accession & Other Names \\
\hline \multirow[t]{4}{*}{ Human } & IFI16 & 3428 & IFI16 & NM_005531.2 & PYHIN2 \\
\hline & IFIX & 149628 & PYHIN1 & NM_198929.4 & \\
\hline & MNDA & 4332 & MNDA & NM_002432.1 & PYHIN3 \\
\hline & AlM2 & 9447 & AlM2 & NM_004833.1 & PYHIN4 \\
\hline \multirow[t]{14}{*}{ Mouse } & Ifi202 & 26388 & Ifi202 & NM_0119140.2 & \\
\hline & Ifi203 & 15950 & Ifi203 & NM_008328.2 & \\
\hline & Ifi203' & 100504283 & Gm16340 & XM_003084464.1 & \\
\hline & Ifi204 & 15951 & Ifi204 & NM_008329.2 & \\
\hline & Ifi205 & 226695 & Ifi205 & NM_172648 & D3', Ifi205a \\
\hline & Ifi206 & 240921 & Gm4955 & XM_136331.8 & \\
\hline & Ifi207 & 226691 & Al607873 & NM_001204910.1 & \\
\hline & Ifi208 & 100033459 & Pydc3 & NM_001162938.1 & \\
\hline & Ifi209 & 236312 & Pyhin1 & NM_175026.2 & Ifix \\
\hline & Aim2/Ifi210 & 383619 & Aim2 & NM_001013779.2 & \\
\hline & Ifi211 & 381308 & Mnda & NM_001033450.3 & D3, Ifi205b, Pyhin3 \\
\hline & Mndal//fi212 & 100040462 & Mndal & NM_001170853.1 & \\
\hline & Ifi213 & 623121 & Pydc4 & NM_001177349.1 & \\
\hline & Ifi214 & - & - & JN200820.1 & \\
\hline \multirow[t]{5}{*}{ Rat } & Aim2 & 304987 & Aim2 & XM_222949.5 & Rhin1 \\
\hline & Rhin2 & 289245 & RGD1562462 & XR_086006.1 & \\
\hline & Rhin3 & 304988 & Ifi204 & NP_001012029.1 & Mnda, rHin-3 \\
\hline & Rhin4 & 498288 & |fi203-ps1 & XR_086004.1 & Ifi203 \\
\hline & Rhin5 & 689152 & LOC689152 & XM_002728037.1 & \\
\hline
\end{tabular}




\section{Gene nomenclature}

PYHIN gene and protein nomenclature has been confused over the years due to the similarity between genes. Early papers on a family member termed D3 [62] show sequence from the Ifi211 gene, although this name also seems to have been used for the Ifi205 gene, which is very similar. What we have termed Ifi211 here has been annotated as Ifi205b in a recent review [30]. However, the N-terminal 200 amino acids encoded by Ifi211 are more closely related to Ifi204 ( $98 \%$ amino acid identity), perhaps indicating recent gene conversion (Additional file 1: Figure S1). Consequently, we favour independent names for these genes. New names for genes have also been introduced during genome annotation on the basis of some inter-species sequence similarities. We show later in this paper that apart from AIM2 there are no direct orthologues between mouse and human. Thus, we propose the simple numbering for mouse genes indicated in Table 1.

\section{The mouse, human and rat protein families}

The domain organisation inferred from cDNA sequences reveals that whilst most proteins have a pyrin domain at the $\mathrm{N}$ terminus and a C-terminal HIN domain, there are also cDNAs coding for proteins with no pyrin domain (p202), with two HIN domains (p202, p204, IFI16) and no HIN domains (p208, p213, AIM2b) (Figure 2). A number of splice variants exist for IFI16, IFIX and Ifi203, detailed elsewhere $[22,63]$. We have identified a splice variant of mouse Aim 2 that would generate a pyrin-only protein, termed here AIM2b (Genbank JQ894737).

\section{Identification of PYHIN genes in a range of species}

Rigorous TBLASTN and iterative PSI-BLAST searches for PYHIN proteins in vertebrates revealed no trace of HIN domains outside of mammals, nor any other closely related domains. Although structural evidence suggests the HIN domain may have evolved from a DNA-binding OB-fold [55], there is now little primary sequence homology between HIN and other DNA-binding domains. PYHIN pyrin domains have some sequence similarity to pyrin domains found in NOD-like receptor proteins. Our searches in non-mammals using PYHIN pyrin domains returned only domains from these other protein families. TBLASTN searches in marsupials found only a single PYHIN coding sequence in each of opossum, Tasmanian devil and wallaby. Thus, at least one PYHIN gene existed prior to the divergence of marsupials and placental mammals. There is no evidence of any such gene in the platypus genome (NCBI Build 1.1, 6-fold coverage). Whether this truly reflects an absence in monotremes, or incomplete genome sequence,

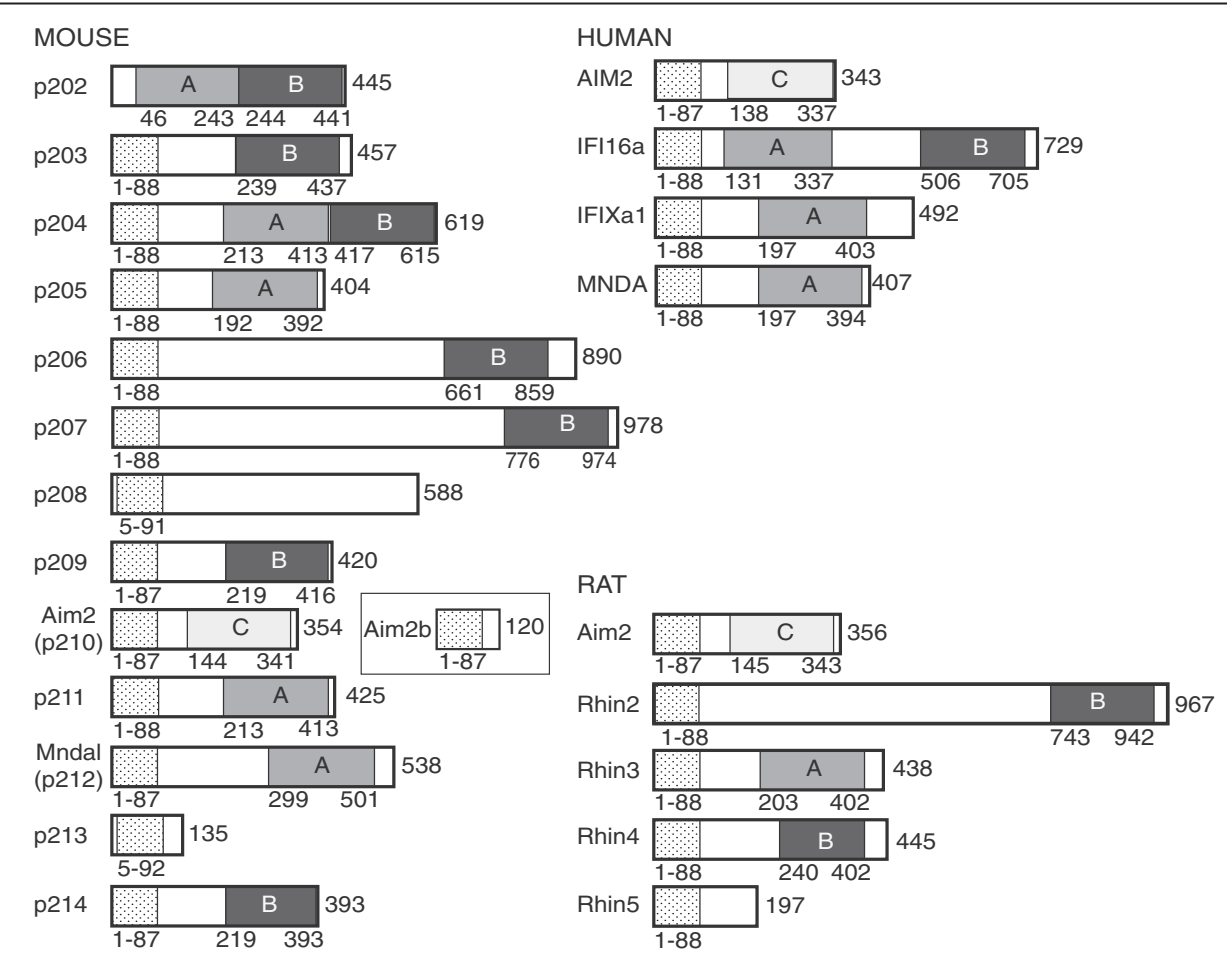

Figure 2 Predicted protein domain organisation derived from CDNA sequences for human and mouse and predicted genes for rat. Pyrin domains are indicated by stippled boxes, and the HIN domain subtypes (A, B or C) are shown. Only a single splice variant is shown for human IFI16 and IFIX, with complete details summarised previously [22]. Mouse p203 also has known splice variants [63]. Regions of sequence similarity among mouse proteins and the relationship between mouse and rat proteins are summarised in Additional Files 1 and 6. 
remains to be established. PYHIN gene sequences were identified in all major groups of mammals, except bats.

\section{Phylogenetic analysis supports HIN domain subtypes}

To examine the evolution of the gene cluster during mammalian radiation, we used sequences from species in each of the major clades on the mammalian species tree (Table 1 and Additional File 2: Table S1). Evident shuffling of pyrin and HIN domain coding sequences between genes in mouse and in other species, as well as highly variable sequences in the region between pyrin and HIN domains meant that phylogenetic analyses of the protein sequences as a whole were not informative. Consequently, pyrin and HIN domains were used separately for analysis, with alignments of these domains provided in Additional File 3: Figure S3 and Additional File 4: Figure S4. Within the species shown, we extracted all the available complete (two-exon) HIN domain sequences.

Trees were generated by Bayesian as well as maximum likelihood approaches. A HIN domain phylogenetic tree derived from Bayesian analysis is shown in Figure 3, rooted with marsupial sequences. Overall, the tree topology was very similar by the two methods as indicated in Figure 3. This revealed three distinct clades of placental mammal sequences, consistent with previous assignment of HIN-A, HIN-B and HIN-C type domains [22]. The marsupial sequences cluster separately, and we have termed these HIN-D. The HIN-C domain is uniquely found in AIM2-like sequences, present at a maximum of one copy in each genome. A clear difference in the role of HIN-A, $-\mathrm{B}$, and $-\mathrm{C}$ domains is yet to be established, although recombinantly expressed IFI16 HIN-A and HIN-B domains differ in their ability to bind DNA [13]. The maintenance of distinct HIN-A and HIN-B

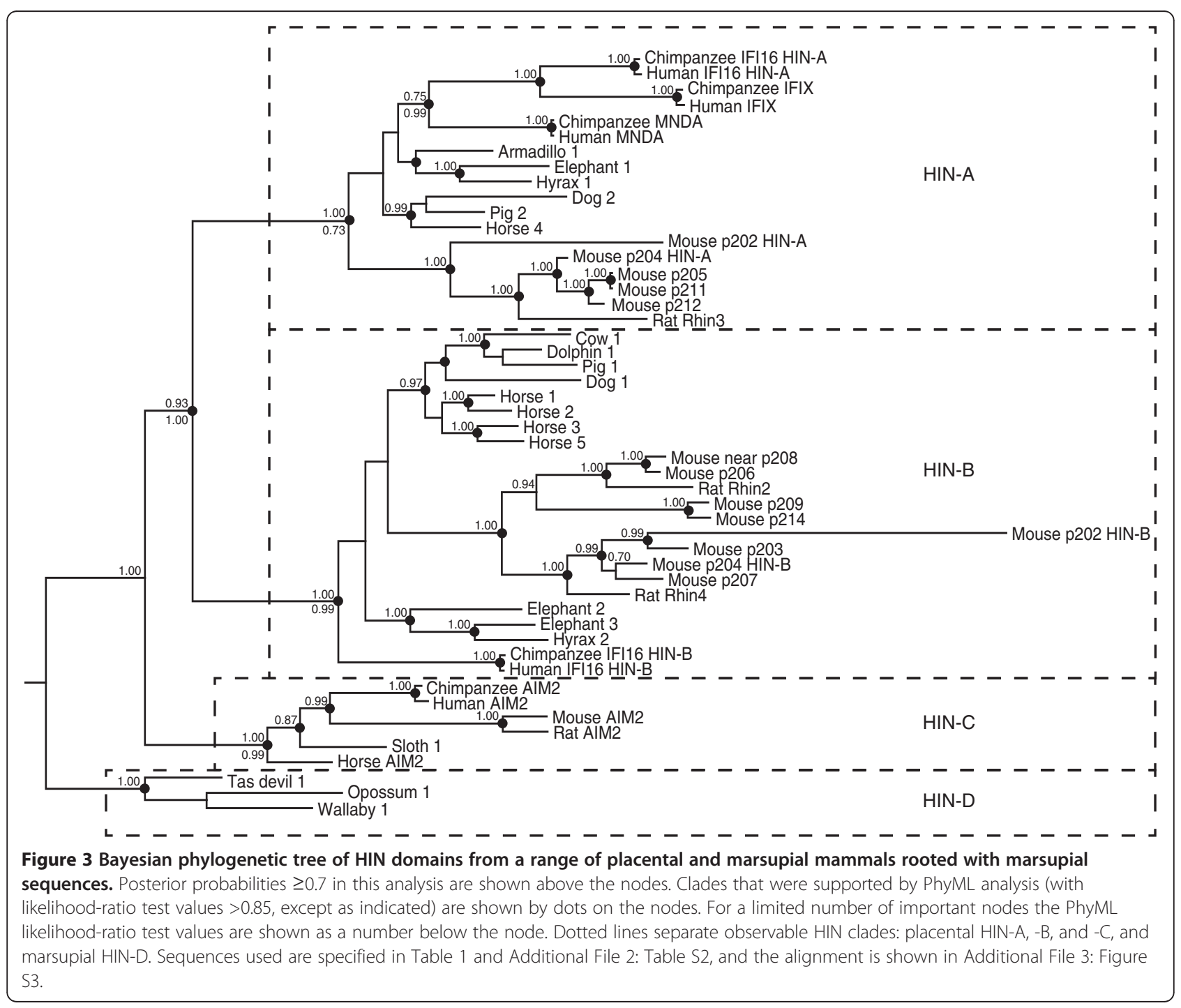


sequences amongst diverse species suggests that they may recognise different structures or sequences of DNA, and consequently be optimal for recognition of distinct classes of pathogens. Notable from this analysis is the branch length for mouse p202 HIN domains, particularly the HIN-B domain, indicating a rapid divergence from other mouse HIN domains.

\section{Pyrin domain phylogeny shows the distinct nature of AIM2}

Similar approaches were taken to generate phylogenetic trees for PYHIN pyrin domains, rooted with marsupial sequences. The resolution of these trees was limited by the short sequence of the pyrin domain (88 amino acids). However, the majority of clades were predicted similarly by Bayesian and maximum likelihood methods, as indicated in Figure 4. The major result is the demonstration of two markedly separate clades amongst the placental mammal proteins, one containing AIM2 orthologues, and another encompassing all other ("IFI") PYHINs (Figure 4). The large divergence between the AIM2 and IFI sequences is evident by the long branch lengths separating these clades.

The maintenance of such a distinct pyrin domain in AIM2 suggests it has a different role from that of the other PYHIN proteins. Divergence of AIM2 and IFI pyrin domains occurred prior to placental mammal speciation, since diverse mammalian species have maintained distinct AIM2 and IFI pyrin sequences. In AIM2, the HIN domain binds DNA and the pyrin domain recruits ASC and nucleates the formation of the DNA inflammasome. Earlier results suggested that the AIM2 pyrin domain, but not other human PYHIN factors, could bind ASC [2]. Recent work suggests that IFI16

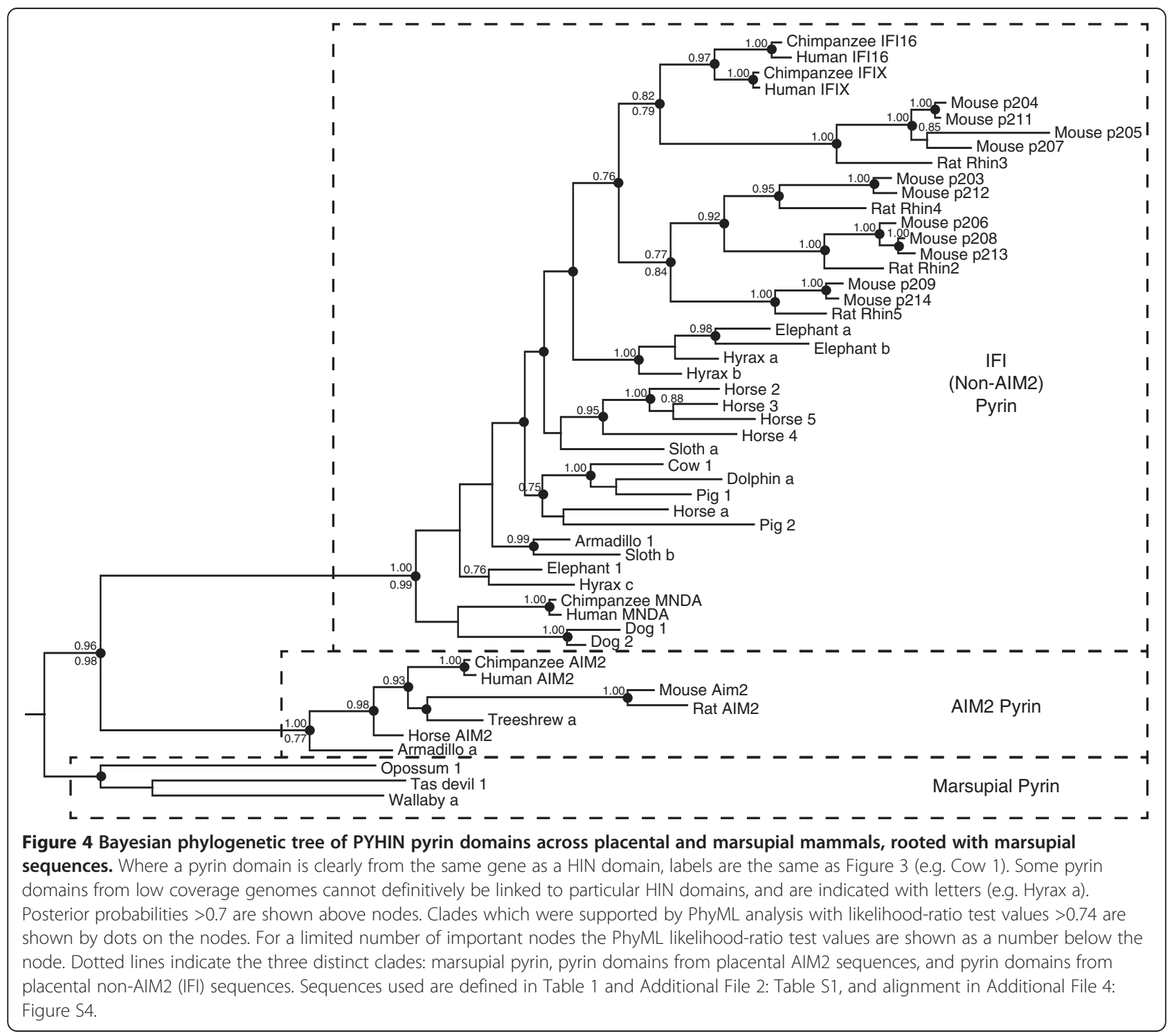


binds viral DNA in the nucleus and initiates inflammasome responses [12], although a direct interaction with ASC has not been demonstrated. Further work to examine proteins interacting with the IFI pyrin domains is warranted.

Amongst the non-AIM2 sequences, the pyrin tree topology (Figure 4) is markedly different from the HIN tree (Figure 3). There is no distinction between the pyrin domains of HIN-A and HIN-B containing proteins. In some cases, there has been evident gene conversion or domain shuffling which has maintained similarity of pyrin domain sequences within a species. For example, the two dog pyrin sequences are closely related, although one dog gene contains a HIN-A and one a HIN-B.

\section{Multiple species have AIM2 pseudogenes}

AIM2 is required for optimal defence against some viral and bacterial pathogens in mouse [6,7]. In contrast to the variable expansions of the other PYHIN family members, we have observed AIM2 in only one copy per genome. Surprisingly, we found no intact AIM2, but evidence for an AIM2 pseudogene in cow, llama, dolphin and sheep (Figure 5, Additional File 5: Figure S5) as well as elephant and dog (not shown). These sequences all encode HIN-C, more similar to AIM2 than other human IFI proteins (Additional File 5: Figure S5), but contain frame shifts and/or multiple stop codons. Cow, llama, dolphin and sheep are all part of the Cetartiodactyla [64], and there may have been basal loss of AIM2 in the evolution of this clade (Figure 5). Pig also falls within this group, and we could find no discernible AIM2 gene or pseudogene sequence within the available pig genome (Ensembl Sscrofa9), which has four-fold coverage. Horse appears to have an intact AIM2 gene, whilst dog has a pseudogene. The phylogenetic relationship between horse, dog and the Cetartiodactyla is controversial [65], and an independent origin for the dog pseudogene, as shown in Figure 5, cannot be confirmed. However, generation of the elephant pseudogene must have been an independent event (Figure 5). It cannot be excluded that further sequencing may reveal intact AIM2 in some of these species. However, the neighbouring CADM3 gene can be reliably identified in the published genomes of all these species except sheep, which has relatively low coverage. Although AIM2 is of demonstrated importance in mouse [6,7], the probable loss of AIM2 in some species suggests they have evolved alternate mechanisms to cope with DNA viruses and intracellular bacteria.

\section{Lineage-specific gene family expansions}

There are variable expansions of HIN-A and HIN-B encoding genes in different species, most prominently in

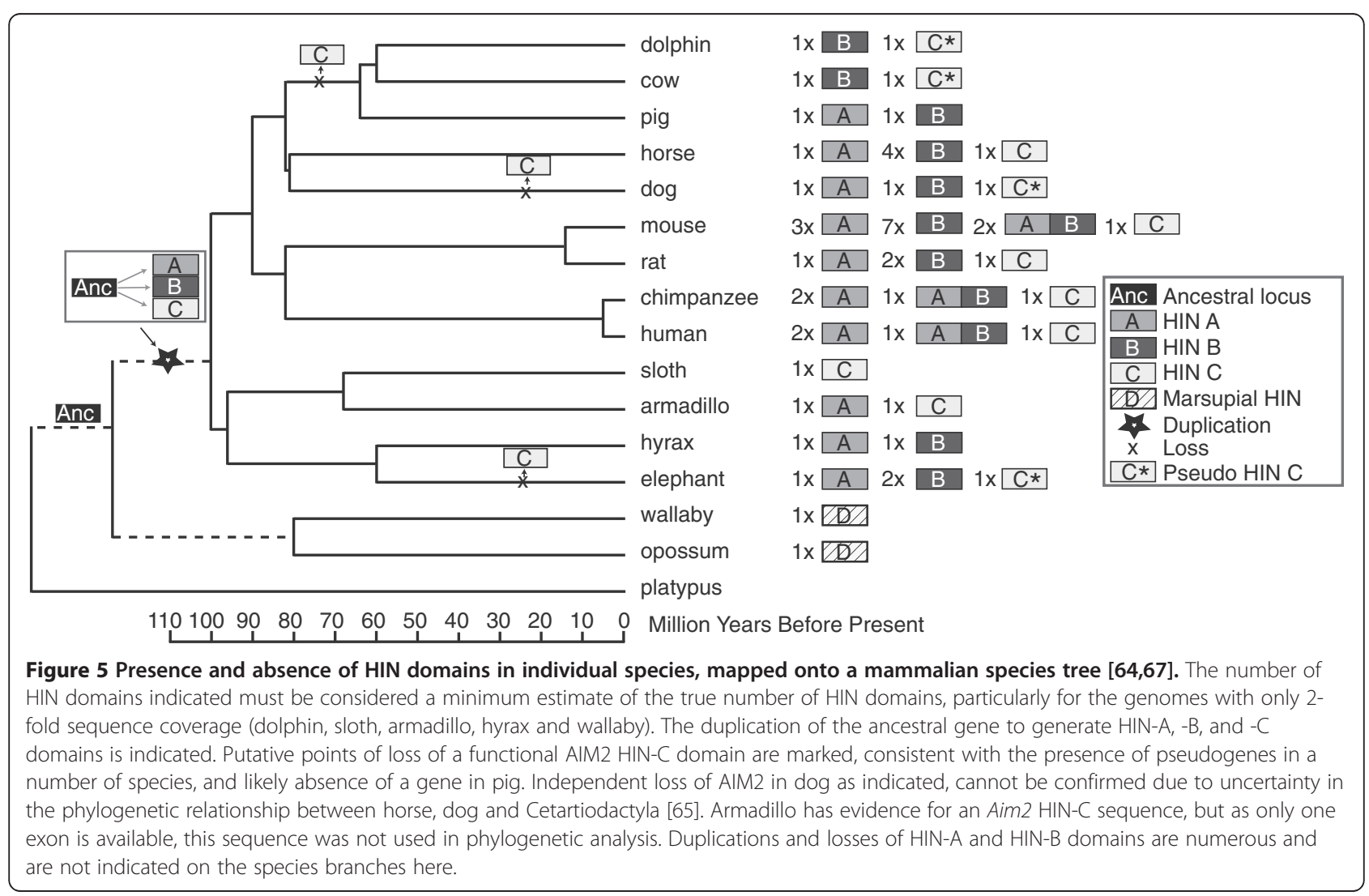


mouse. Based on the phylogenetic analyses, clusters of mouse genes appear to have arisen by duplication after separation from the rat lineage (Figures 3 and 4). Between one and four mouse genes are co-orthologous to each of the five rat genes. Rhin2 is orthologous to Ifi206 (Figures 3 and 4) and is conserved in location in the locus adjacent to Aim2 (Figure 1). Rhin3 and Rhin4 are orthologous to clusters of mouse HIN-A and HIN-B containing genes respectively. Rhin5 is lacking a HIN domain coding sequence, but is otherwise orthologous to Ifi214 and Ifi209. The relationship between mouse and rat proteins is summarised in Additional File 6: Figure S2. Apart from gene duplication in the mouse, there has been some domain swapping between paralogues and this provides a patchwork of sequence similarity between different proteins. For example, p212 is a hybrid between p203 and p205-like sequences $[28,66]$. The regions of sequence similarity between different mouse proteins are summarised in Additional File 1: Figure S1.

Lineage-specific duplications are also evident within horse, which has 6 recognisable genes, four of which form a clade on the pyrin tree (Figure 4). In contrast, the cow genome (UMD3.1 assembly) shows only a single intact PYHIN gene. The specific expansion of the gene family in some species may reflect the evolutionary "arms race" involved in combating infections. Gene duplication and diversification may allow better control of lineage-specific pathogens.

\section{Evolution of the PYHIN family}

To describe the evolution of the PYHIN family, the HIN domain tree was reconciled with a mammalian species tree (Figure $5[64,67])$. Duplication and deletion events were inferred based on the presence or absence of HIN domains and pseudogenes in different species. The model proposes that an ancestral HIN domain was amplified after the divergence of placental mammals and marsupials, and evolved into HIN-A, $-\mathrm{B}$, and $-\mathrm{C}$ in the ancestor of all placental mammals (Figure 5). We found evidence for sequences for HIN-A, HIN-B and HIN-C domains within the Afrotheria (elephant and hyrax) and Xenarthra (armadillo and sloth), which are the most basal groups of placental mammals (Figures 3 and 5). The losses of the unique AIM2 HIN-C domain described above are indicated in Figure 5. Some species show numerous pseudogenes containing HIN-A and HIN-B domains, but these are not considered here. The final number and composition of PYHIN proteins differs greatly between species, although dolphin, armadillo, sloth and hyrax genomes have been sequenced only at low coverage, and the genes indicated are likely a minimum estimate of the true number of genes in these species.
Branch lengths for both HIN and pyrin trees predict that AIM2 is somewhat closer in sequence to the PYHIN gene in the last common ancestor of placental mammals and marsupials, than are the other IFI sequences (Figures 3 and 4). This is most pronounced for the pyrin domain sequences (Figure 4). It is reasonable to propose that the ancestral function of the gene was similar to AIM2, in nucleating the inflammasome through recruitment of ASC. This function for the ancestral PYHIN would be expected, since ASC binding is a function also conserved in more distant pyrin domain-containing proteins such as NLRP3.

\section{Orthology between mouse and human}

The identification of mouse and human orthologues is relevant to the use of mouse models for the study of human cellular processes and disease. Human and mouse AIM2 were the only direct orthologues identified between these species based on the phylogenetic analyses of both HIN and pyrin domains (Figures 3 and 4). The human IFI16 and IFIX proteins result from gene duplication within the primate lineage. The HIN-A domains of these proteins also cluster with higher probability with human and chimpanzee MNDA than with the clade of rodent HIN-A domains. This is consistent with speciation of rodent and primate lineages prior to amplification of the HIN-A domain. The C-terminal HIN domain in IFI16 is the sole human HIN-B domain. Rodent HIN-B domains are all more similar to one another than they are to the human. Thus there are no direct mouse orthologues of human IFI16, IFIX or MNDA. However, the pyrin domain tree shows that mouse p204, p211, p205 and p207 form a clade with human IFI16 and IFIX, rather than with other mouse proteins. If there is any functional distinction between the IFI pyrin domain clades, then these mouse proteins might have the closest effector function to IFI16 and IFIX.

Whilst it is tempting to infer common ancestry on the basis of shared arrangements of domains (i.e. IFI16 looks like p204), it is most likely that the acquisition of the double HIN domain structure in IFI16 and p204 arose by independent events, as there is no evidence for tandem HIN domains in any other non-primate species, including rat, and the phylogenetic analyses of HIN domain sequences did not support them as being orthologous. Despite the lack of 1:1 orthology between mouse and human in the non-AIM2 proteins, they may all be functionally quite similar. Gene duplications within a species could permit the evolution of different expression patterns or different intracellular locations, or may contain amino acid changes that circumvent the efforts of pathogens to evade detection. Gene expression patterns were investigated, to see whether the gene amplification had generated differential expression patterns. 


\section{Expression of mouse genes}

Mouse AIM2 expression analysed by northern blot, showed predominant expression of AIM2 mRNA in spleen and large intestine (Figure 6). Real-time PCR generated a similar pattern of expression (Figure 7a). Previous work on human AIM2 found expression predominantly in spleen, with detectable mRNA in small intestine and peripheral blood but levels below detection in most other tissues tested [25]. Primers were designed for real-time PCR of all mouse family members, and tested for off-target amplification using cloned cDNAs from all mouse PYHIN genes. We were unable to design primers to specifically amplify Ifi211, due to its near identity to Ifi204 at the $5^{\prime}$ end, and high similarity to Ifi205, 204 and 212 in the rest of the gene. Screening of mouse tissues showed a variety of expression patterns. Spleen was a major site for most but not all factors. Tissues were obtained from C57BL/ 6 mice, which unlike other strains express negligible amounts of Ifi202 mRNA in spleen [68]. However, C57BL/6 skin showed detectable Ifi202 expression. Ifi205, 204 and 207 showed strongest expression in skin, and interestingly these form a clade on the pyrin tree, together with Ifi211 (Figure 4), for which we could not analyse expression. This group forms a larger clade with the pyrin domains of human IFIX and IFI16 (Figure 4). Apart from hematopoietic cell expression, IFI16 is expressed in epithelial cells and vascular endothelial cells [69-71]. It is prominently expressed in the lower proliferating layers of epithelia, including the skin [69]. Defence of proliferating keratinocytes against infection is a likely role for this group of skin-expressed human and mouse proteins.

Ifi204 was also well expressed in liver, heart and skeletal muscle, and extensive work implicates p204 in muscle differentiation [39]. One paper has suggested that Ifi203 expression at mRNA and protein level is limited to the liver [63], although we and others find it more widely expressed, with strongest expression in the spleen [28]. Overall, our results agree very well with those obtained for expression of Ifi203-205 and Mndal/ Ifi212 in BALB/c mouse tissues by Zhang et al. [28], and provide data for an extra seven genes.

PYHIN genes have been predominantly studied in hematopoietic cells, and here we have compared expression of the twelve genes in splenic $\mathrm{T}$ and $\mathrm{B}$ cells, as well as in bone marrow-derived macrophages (BMM) and thioglycollate-elicited peritoneal macrophages (Figure 7b). Aim2 was readily detectable in all cells. Some genes such as Ifi203, 206 and 213 were expressed well except in elicited macrophages. Ifi204, in contrast, was relatively myeloid restricted amongst the immune cell types, but is not restricted to myeloid cells since it had highest expression in skin (Figure 7a). The duplication of PYHIN genes allows for evolution of distinct patterns of regulation of similar genes. An example of this is seen with Ifi209 and Ifi214, which result from recent duplication. Although on a tissue level they were similarly spleen-specific, on a cellular level Ifi209 was expressed in T, B and BMM, whereas Ifi214 was T and B cell-specific.

Lastly, we examined expression in BMM from three different mouse strains (Figure 7c). Ifi202 showed marked differential expression, in agreement with previous work $[4,68,72]$, and has been investigated as a possible susceptibility factor for lupus in the NZB mouse strain [41]. The lack of expression of Mndal/Ifi212 in NZB is due to the lack of this gene in DBA and related strains [28]. There was no expression of Ifi206, Ifi209,

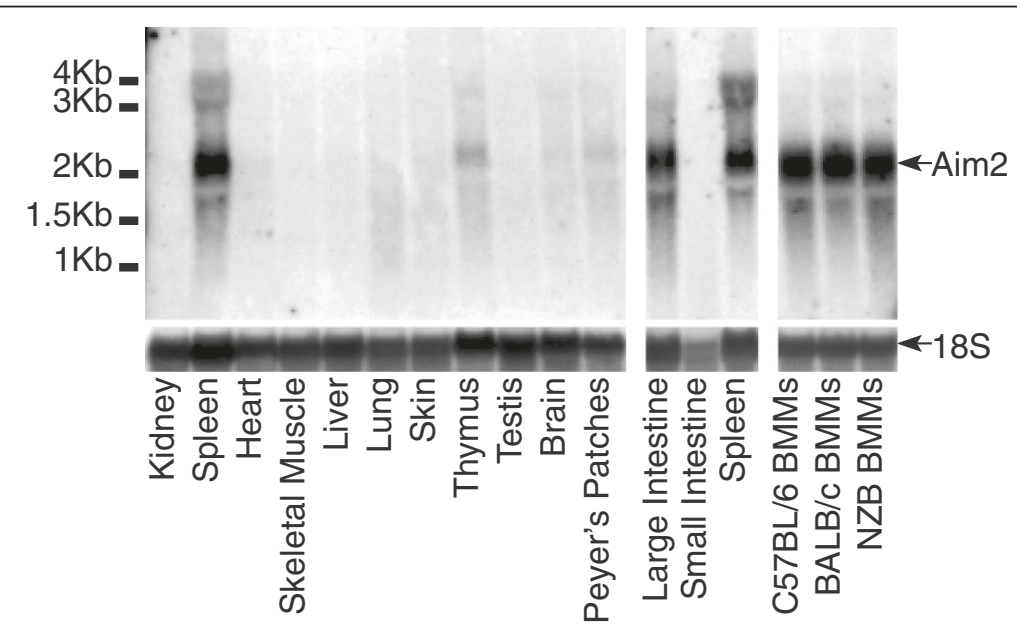

Figure 6 Northern blots for Aim2 expression in C57BL/6 mouse tissues, as well as bone marrow derived macrophages (BMM) from three mouse strains. Results for $18 \mathrm{~S}$ rRNA are shown as a loading control. Tissues were perfused with saline to reduce blood cell contamination. Results are representative of two independent tissue samples. 


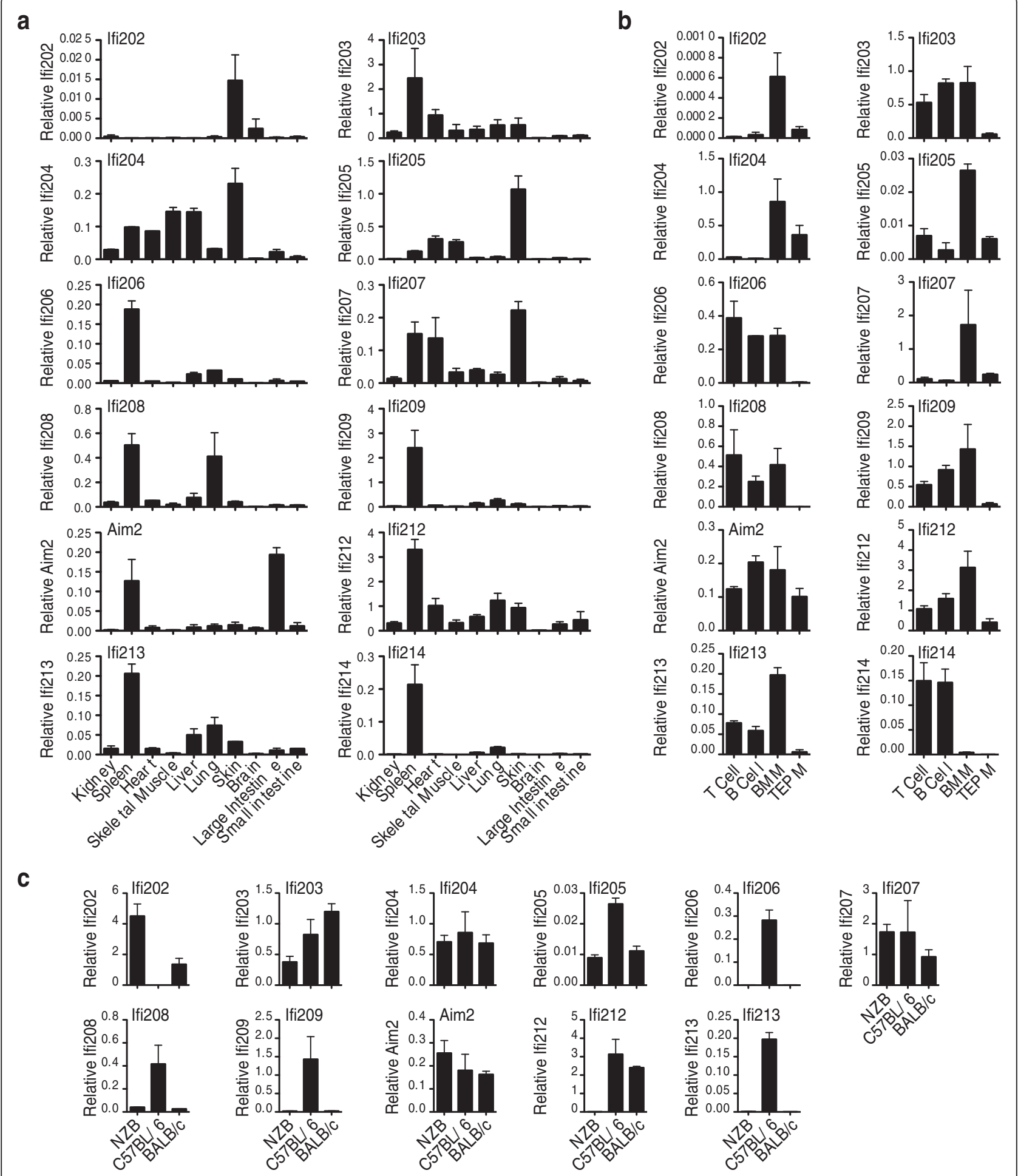

Figure 7 Expression of mouse PYHIN genes in perfused C57BL/6 mouse tissues (a), in various C57BL/6 mouse immune cells - splenic T and B cells, BMM and thioglycollate elicited peritoneal macrophages (TEPM) (b), and in BMM from three different mouse strains (c). Real time PCR results for each gene were normalised to the average of four housekeeping genes, which was found to give a relatively stable signal between tissues. Primers were tested to ensure lack of significant amplification of non-target PYHIN cDNAs. Results shown are the mean and range derived from duplicate RNA preparations. 
and Ifi213, and minimal expression detected for Ifi208 in both NZB and BALB/c BMM. Interestingly, these genes are all clustered at one end of the gene array, near Aim2 (Figure 1). This suggests that this region may be lacking in these strains. Strain-specific data are not shown for Ifi214, since this gene is barely expressed in BMM (Figure 7b).

The inter-strain differences complicate analysis of the AIM2 gene trap knockout mice [6,7]. The gene trap allele is derived from 129 mouse ES cells and is generally used on a mixed 129 and C57BL/6 background. In the knockout mice, the PYHIN locus and chromosome 1 regions surrounding the null AIM2 allele will derive only from 129 mice, whereas littermate controls with intact AIM2 will carry the C57BL/6 gene array. Use of AIM2 knockout mice on a pure background will thus be essential for many studies of AIM2 function in disease.

In summary, spleen and skin were the two most prominent sites of mouse PYHIN expression, consistent with a role in immune defence. Gene family expansion in mouse has allowed some diversification of expression patterns. Human and mouse PYHIN genes are variously expressed in a range of immune cell types and also epithelial and endothelial cells, although the genes do not obviously fill identical "niches". For example MNDA is strongly myeloid restricted [73,74], but there seems to be no similarly expressed mouse gene. Apart from AIM2, the lack of concordance of expression patterns and sequence between mouse and human genes emphasises the need to consider the roles of individual proteins separately in the two species.

\section{Conclusions}

Defences against invading DNA are likely to be found within all species, and are of course well characterised in the bacterial restriction/modification systems. The evolution of the first PYHIN protein is likely to have provided a new effector system for combating the threats indicated by stray DNA within mammalian cells. AIM2 appears less changed from the ancestral protein than are the other PYHIN proteins, and we anticipate the ancestral protein functioned similarly, in recruitment of the inflammasome in response to cytosolic DNA. A role for combating infectious threats is established for AIM2 $[6,7]$, with both cytokine production and cell death likely to be important PYHIN-mediated defences. Duplication of the ancestral gene in the placental mammals may have enabled defence against organisms with a range of different replicative and evasion strategies. Since the HIN domain is the DNA-binding domain, the evolution of HIN-A, -B, and -C subtypes in placental mammals may have allowed specialisation to recognise different DNA structures. Differences in DNA-binding preferences of these domains are yet to be established. The pyrin domain evolution is constrained by maintenance of protein-protein interactions, such as recruitment of ASC for the AIM2 pyrin. Differences in interaction partners between AIM2 and the other PYHIN proteins warrants investigation, given the distinct natures of their pyrin domains. Further gene expansions prominent in mouse and horse may have provided particular advantage in combating species-specific infections. However, it is also possible that a driving force in evolution of the gene family is defence against high activity of endogenous retroelements, which create reverse transcribed DNA. Although evolution has been fuelled by waves of activity of retroelements [75], levels of activity need to be controlled to prevent excessive genome damage within each generation, and within somatic cells. Retroelements are generally silenced by methylation, and there is increasing evidence for their role in cancer and autoimmunity $[76,77]$. Cell death, as is mediated by AIM2 in response to cytosolic DNA, may be an appropriate response to eliminate cells where retroelements are inappropriately active. Interestingly, the estimated ages of retroelements in human and mouse genomes show ongoing high activity in the mouse genome but not human genome [78]. Thus it is conceivable that PYHIN expansion in the mouse could be driven by a need to control retroelement activity, as well as infectious disease.

\section{Methods}

\section{cDNA cloning of mouse PYHIN family}

To find novel PYHIN family coding sequences, DNA sequence based on the Pfam Pyrin domain was used to screen the NCBI Riken Transcripts Database. The NCBI databases and Ensembl genome browser also provided predicted genes in the PYHIN locus. Primers were designed to amplify complete coding sequences of published and novel mouse PYHIN genes, and PCR reactions were performed on cDNA from C57BL/6 mouse spleen and cloned into pEF6-TOPO-TA vector (Invitrogen).

\section{Genome searches for PYHIN family members}

To assess the range of species in which PYHIN proteins could be discerned, TBLASTN searches were conducted against the GenBank whole-genome shotgun sequence database, using human AIM2 and IFI16 protein sequences and an expect threshold (E) of 10. From this a number of genomes spanning major placental mammal lineages, as well as all three available marsupial genes were selected for comprehensive analysis of PYHIN genes. Genomes analysed were: human (Homo sapiens NCBI v36.3), mouse (Mus musculus MGSCv37.2), rat (Rattus norvegicus RGSCv3.4), horse (Equus caballus EquCab2), dog (Canis lupus familiaris CanFam2.0), cow (Bos taurus UMD3.1), pig (Sus scrofa ENS:Sscrofa9), 
chimpanzee (Pan troglodytes CHIMP2.1.4), elephant (Loxodonta Africana loxAfr3), dolphin (Tursiops truncates turTru1), hyrax (Procavia capensis proCap1), sloth (Choloepus hoffmanni choHof1), armadillo (Dasypus novemcinctus dasNov2), opossum (Monodelphis domestica MonDom5), wallaby (Macropus eugenii Meug_1.0), and Tasmanian devil (Sarcophilus harrisii DEVIL7.0). Ensembl and NCBI genomic sequence databases were searched using TBLASTN and individual pyrin and HIN domain amino acid sequences from human AIM2 and IFI16, using default settings, and also with the gap opening penalty reduced to -9 and the expect threshold increased to 10. Genomes were also searched using a predicted protein from within the same genome to detect potential paralogs not detected by searching with human AIM2 or IFI16. The rat, opossum, dog and horse genomes were also searched using HIN and pyrin domain motifs using the MEME [79] and MAST v4.3.0 [80] software suite. Motifs that crossed different exons of the HIN domain were avoided. The motifs were used to search Ensembl $a b$ initio predicted proteins. When novel unannotated genes were detected, genomic sequences containing PYHIN genes were examined for potential splice sites in conserved positions, and exons encoding a pyrin domain or the two exons encoding the HIN domain were extracted.

\section{Analysis of platypus and non-mammalian genomes}

The platypus genome (Ornithorhynchus anatinus Build 1.1) was searched using TBLASTN for the full-length predicted PYHIN protein from opossum and full-length human IFI16. In another approach, all HIN domains identified in the $6 x$ coverage mammalian genomes were used to build a profile hidden Markov model with the software HMMER [81], which was then used to screen the platypus $a b$ initio peptide predictions available from Ensembl. An inferred ancestral HIN domain sequence from the node that predates the split between HIN-A, $-\mathrm{B}$ and $-\mathrm{C}$ domains was also used to perform this search. The genomes of chicken (Gallus gallus release 2.1), frog (Xenopus tropicalis version 4.1), anole lizard (Anolis carolinensis AnoCar1.0) and zebrafish (Danio rerio Zv8), available via NCBI and Ensembl, were searched using TBLASTN with the HIN domain from opossum, and human AIM2 and IFI16. None of these searches, nor the general search of all shotgun genomic sequences, yielded any trace of PYHIN genes in monotremes or nonmammals.

\section{Phylogenetic analyses}

Phylogenetic analyses were performed separately on pyrin and HIN domains. The linking region between these domains was not used in the alignments as it is highly variable between individual proteins, and it was not possible to identify this region in the low coverage genomes. Alignments were constructed using ClustalW2 $[82,83]$.

Phylogenetic inference was performed using Bayesian and maximum-likelihood approaches. For Bayesian analyses we used MrBayes v3.1.2 [84], running 2 million generations and 4 chains for each analysis, setting a burn-in of 2500 samples and sampling the tree space every 100 generations. Model jumping between fixedrate amino acid models was used to determine the mostsuitable substitution model, otherwise using default parameters. All analyses favoured the Jones substitution model [85]. Convergence was judged using the standard deviation of split frequencies and the plot of log likelihoods. Rooted trees were drawn using Mesquite v2.6 [86].

Maximum-likelihood analyses were performed using PhyML 3.0 [87] under the LG substitution model [88] with 4 substitution rate categories. The proportion of invariable sites and the gamma shape parameter were estimated from the data. We used 10 random starting trees, and subtree pruning and regrafting (SPR) [89] to search tree space. Both tree topology and branch lengths were optimized to maximize the likelihood. Branch support was estimated using 100 bootstrap replicates, and by calculating an approximate likelihood-ratio test [90].

\section{Isolation of mouse splenic immune cells}

Mice were used as a source of tissues, under approval from the University of Queensland animal ethics committee (Approval number IMB/874/08). Splenocytes from C57BL/6 mice were harvested by homogenization of mouse spleens and red blood cells lysed by standard Gey's solution procedure. CD19+ B cells and CD90.2+ T cells were isolated by positive selection using MACS microbeads, run according to manufacturer's instructions (Miltenyi Biotec) over multiple columns. The purity of $\mathrm{B}$ and $\mathrm{T}$ cells assessed by flow cytometry was $>98 \%$. Bone marrow-derived macrophages from BALB/c, C57BL/6 or NZB mice were derived and cultured as described [91]. NZB mice were supplied by Kew animal house (Walter and Eliza Hall Institute, Australia), BALB/c by Animal Resources Centre, Perth, and C57BL/6 by University of Queensland Biological Resources. Thioglycollate elicited peritoneal macrophages were harvested from C57BL/6 mice and cultured as described [92].

\section{RNA isolation and real-time PCR}

RNeasy Total RNA isolation kits (QIAGEN) were used to isolate RNA from mouse cell preparations, as well as from perfused C57BL/6 mouse tissues, according to standard protocols (QIAGEN). All tissues except bone marrow, spleen, liver, kidney and brain included a Proteinase $\mathrm{K}$ digestion step. cDNA was synthesised as 
previously described [93]. Where there are known splice variants of mouse PYHIN mRNAs, primers were designed to detect all variants (Additional File 7: Table S2). Efficiency of amplification was checked for the target gene. Specificity of each of the mouse PYHIN primer sets was assessed by running $\mathrm{qPCR}$ using a standard amount of each of the various different cloned PYHIN cDNAs as templates. Specificity was considered to be adequate when amplification of the target gene was achieved more than 10-12 cycles ahead of any other gene. Appropriate specificity was not achieved for Ifi211, and it could not be analysed here. Primers for Ifi209 also amplified Ifi214. However, primers for Ifi214 were specific and samples had a low level of Ifi214, which had minimal effect on the Ifi209 expression data.

Levels of gene expression are shown for the test gene relative to the average expression of four house-keeping genes (Tbp, Hprt, Cxxc1, Rpl13A), performed in duplicate. These were quantified by RT PCR using the $\triangle C T$ method [94] as described [4]. Single exon primers were also tested against reactions containing no reverse transcriptase to ensure no genomic DNA contamination.

\section{Northern Blotting}

$10 \mu \mathrm{g}$ of tissue RNAs and $7.5 \mu \mathrm{g}$ of immune cell RNAs were resolved on a $1 \% \mathrm{MOPS} /$ formaldehyde gel. The RNA was transferred to a Zeta-probe membrane (BioRad) by capillary blotting, and hybridised with AIM2 coding region cDNA probe at $65{ }^{\circ} \mathrm{C}$ or an oligonucleotide probe to $18 \mathrm{~S}$ rRNA at $42{ }^{\circ} \mathrm{C}$ according to manufacturer's protocols (Biorad). The AIM2 probe was labelled as per the Amersham MegaPrime DNA Labelling System (GE Healthcare), and the $18 \mathrm{~S}$ rRNA probe was labelled using $\gamma^{32}$ P-ATP and polynucleotide kinase.

\section{Additional files}

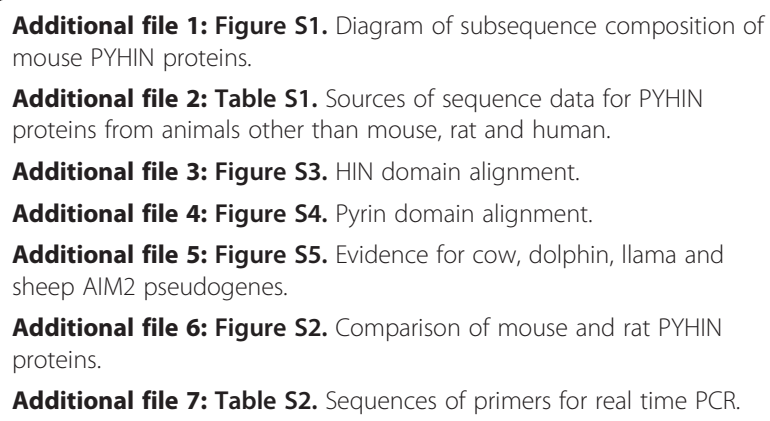

Additional file 6: Figure S2. Comparison of mouse and rat PYHIN proteins.

Additional file 7: Table S2. Sequences of primers for real time PCR.

\section{Abbreviations}

AIM2: Absent in melanoma 2; ASC: Apoptosis-associated speck-like protein containing a CARD; BMM: Bone marrow derived macrophages; BRCA1: Breast cancer 1, early onset; BRCA2: Breast cancer 2, early onset; CADM3: Cell adhesion molecule 3; CARD: Caspase recruitment domain; CXXC1: CXXC Finger protein 1; DDX41: DEAD (Asp-Glu-Ala-Asp) box polypeptide 41; dsDNA: Double stranded DNA; HIN-200: Hematopoietic, interferon-inducible nuclear proteins with a 200 amino acid repeat; HPRT: Hypoxanthine guanine phosphoribosyl transferase; IFI200: Interferon inducible gene family; IFI16: Interferon inducible protein 16; IFIX: Interferon inducible protein $X$; IFN- $\beta$ : Interferon- $\beta$; MCMV: Mouse cytomegalovirus; MNDA: Myeloid nuclear differentiation antigen; Mndal: MNDA-like; NLRP3: Nod-like receptor family, pyrin domain containing 3; OB-folds: Oligonucleotide/oligosaccharide binding folds; prolL-1 $\beta$ : Pro-interleukin-1 $\beta$; prolL-18: Pro-interleukin-18; PYHIN: Pyrin and HIN domain-containing; Rhin: Rat HIN-200 family member; RPL13A: Ribosomal protein L13a; SPTA1: Spectrin alpha chain; ssDNA: Single stranded DNA; TBP: TATA box binding protein.

\section{Competing Interests}

The authors have no competing interests to declare.

\section{Authors' Contributions}

JAD- cloning CDNAs and sequencing, bioinformatic searches, expression analysis, manuscript preparation, EZC- bioinformatic searches, expression analysis, MNW- purification of mouse B and T cells, KS- expression studies, MJS- mouse tissue CDNA, TLR- cloning mouse CDNAs, MAR- oversight of phylogenetic strategy, KSK- supervision of bioinformatic searches, phylogenetic analysis, manuscript preparation, KJS- project initiation and oversight, bioinformatic searches, manuscript preparation. All authors read and approved the final manuscript.

\section{Acknowledgements}

KJS is supported by Australian Research Council (ARC) Future Fellowship FT0991576, and MJS by an ARC Future Fellowship FT100100657 and an honorary National Health and Medical Research Council of Australia (NHMRC) Senior Research Fellowship 1003470. KS is supported by C.J. Martin fellowship 490993 from the NHMRC, and MNW by Queensland government Smart State Fellowship. Research was supported by NHMRC grants 631472 and 1010887.

\section{Author details}

'The University of Queensland, School of Chemistry and Molecular Biosciences, Brisbane, Qld 4072, Australia. ${ }^{2}$ Queensland Institute of Medical Research, 300 Herston Road, Brisbane, Qld 4006, Australia. ${ }^{3}$ The University of Queensland, Brisbane, Qld 4072, Australia. ${ }^{4}$ The University of Queensland, ARC Centre of Excellence in Bioinformatics, Brisbane, Qld 4072, Australia. ${ }^{5}$ The University of Queensland, Centre for Medical Genomics, Brisbane, Qld 4072, Australia.

Received: 21 February 2012 Accepted: 27 July 2012

Published: 7 August 2012

\section{References}

1. Fernandes-Alnemri T, Yu JW, Datta P, Wu J, Alnemri ES: AIM2 activates the inflammasome and cell death in response to cytoplasmic DNA. Nature 2009, 458(7237):509-513

2. Hornung V, Ablasser A, Charrel-Dennis M, Bauernfeind F, Horvath G, Caffrey DR, Latz E, Fitzgerald KA: AIM2 recognizes cytosolic dsDNA and forms a caspase1-activating inflammasome with ASC. Nature 2009, 458(7237):514-518

3. Burckstummer T, Baumann C, Bluml S, Dixit E, Durnberger $G$, Jahn $H$, Planyavsky M, Bilban M, Colinge J, Bennett KL, Superti-Furga G: An orthogonal proteomic-genomic screen identifies AIM2 as a cytoplasmic DNA sensor for the inflammasome. Nat Immunol 2009, 10(3):266-272.

4. Roberts TL, Idris A, Dunn JA, Kelly GM, Burnton CM, Hodgson S, Hardy LL, Garceau V, Sweet MJ, Ross IL, Hume DA, Stacey KJ: HIN-200 proteins regulate caspase activation in response to foreign cytoplasmic DNA. Science 2009, 323(5917):1057-1060.

5. Schroder K, Tschopp J: The inflammasomes. Cell 2010, 140(6):821-832

6. Rathinam VA, Jiang Z, Waggoner SN, Sharma S, Cole LE, Waggoner L, Vanaja SK, Monks BG, Ganesan S, Latz E, Hornung V, Vogel SN, Szomolanyi-Tsuda E, Fitzgerald KA: The AIM2 inflammasome is essential for host defense against cytosolic bacteria and DNA viruses. Nat Immunol 2010, 11(5):395-402.

7. Fernandes-Alnemri T, Yu JW, Juliana C, Solorzano L, Kang S, Wu J, Datta P, McCormick M, Huang L, McDermott E, Eisenlohr L, Landel CP, Alnemri ES: The AIM2 inflammasome is critical for innate immunity to Francisella tularensis. Nat Immunol 2010, 11(5):385-393. 
8. Tsuchiya K, Hara H, Kawamura I, Nomura T, Yamamoto T, Daim S, Dewamitta SR, Shen Y, Fang R, Mitsuyama M: Involvement of absent in melanoma 2 in inflammasome activation in macrophages infected with Listeria monocytogenes. J Immunol 2010, 185(2):1186-1195.

9. Warren SE, Armstrong A, Hamilton MK, Mao DP, Leaf IA, Miao EA, Aderem A: Cutting edge: Cytosolic bacterial DNA activates the inflammasome via Aim2. J Immunol 2010, 185(2):818-821.

10. Fang $R$, Tsuchiya $K$, Kawamura I, Shen $Y$, Hara H, Sakai S, Yamamoto $T$, Fernandes-Alnemri T, Yang R, Hernandez-Cuellar E, Dewamitta SR, Xu Y, Qu H, Alnemri ES, Mitsuyama M: Critical roles of ASC inflammasomes in caspase-1 activation and host innate resistance to Streptococcus pneumoniae infection. J Immuno/ 2011, 187(9):4890-4899.

11. Jones JW, Kayagaki N, Broz P, Henry T, Newton K, O'Rourke K, Chan S, Dong J, Qu Y, Roose-Girma M, Dixit VM, Monack DM: Absent in melanoma 2 is required for innate immune recognition of Francisella tularensis. Proc Natl Acad Sci USA 2010, 107(21):9771-9776.

12. Kerur N, Veettil MV, Sharma-Walia N, Bottero V, Sadagopan S, Otageri $P$, Chandran B: IFI16 acts as a nuclear pathogen sensor to induce the inflammasome in response to Kaposi Sarcoma-associated herpesvirus infection. Cell Host Microbe 2011, 9(5):363-375.

13. Unterholzner L, Keating SE, Baran M, Horan KA, Jensen SB, Sharma S, Sirois CM, Jin T, Latz E, Xiao TS, Fitzgerald KA, Paludan SR, Bowie AG: IFI16 is an innate immune sensor for intracellular DNA. Nat Immunol 2010, 11(11):997-1004

14. Ishikawa H, Ma Z, Barber GN: STING regulates intracellular DNA-mediated, type I interferon-dependent innate immunity. Nature 2009, 461(7265):788-792.

15. Ishii KJ, Coban C, Kato H, Takahashi K, Torii Y, Takeshita F, Ludwig H, Sutter G, Suzuki K, Hemmi H, Sato S, Yamamoto M, Uematsu S, Kawai T, Takeuchi O, Akira S: A Toll-like receptor-independent antiviral response induced by double-stranded B-form DNA. Nat Immunol 2006, 7(1):40-48.

16. Stetson DB, Medzhitov R: Recognition of cytosolic DNA activates an IRF3dependent innate immune response. Immunity 2006, 24(1):93-103.

17. Tanaka Y, Chen ZJ: STING specifies IRF3 phosphorylation by TBK1 in the cytosolic DNA signaling pathway. Sci Signal 2012, 5(214):ra20.

18. Cavlar T, Ablasser A, Hornung V: Induction of type I IFNs by intracellular DNA-sensing pathways. Immunol Cell Biol 2012, 90(5):474-482.

19. Zhang Z, Yuan B, Bao M, Lu N, Kim T, Liu YJ: The helicase DDX41 senses intracellular DNA mediated by the adaptor STING in dendritic cells. Nat Immunol 2011, 12(10):959-965.

20. Deschamps S, Meyer J, Chatterjee G, Wang H, Lengyel P, Roe BA: The mouse Ifi200 gene cluster: genomic sequence, analysis, and comparison with the human HIN-200 gene cluster. Genomics 2003, 82(1):34-46.

21. Choubey D, Snoddy J, Chaturvedi V, Toniato E, Opdenakker G, Thakur A, Samanta $H$, Engel DA, Lengyel P: Interferons as gene activators. Indications for repeated gene duplication during the evolution of a cluster of interferon-activatable genes on murine chromosome 1. J Biol Chem 1989, 264(29):17182-17189.

22. Ludlow LE, Johnstone RW, Clarke CJ: The HIN-200 family: more than interferon-inducible genes? Exp Cell Res 2005, 308(1):1-17.

23. Trapani JA, Browne KA, Dawson MJ, Ramsay RG, Eddy RL, Show TB, White PC, Dupont B: A novel gene constitutively expressed in human lymphoid cells is inducible with interferon-gamma in myeloid cells. Immunogenetics 1992, 36(6):369-376.

24. Briggs JA, Burrus GR, Stickney BD, Briggs RC: Cloning and expression of the human myeloid cell nuclear differentiation antigen: regulation by interferon alpha. J Cell Biochem 1992, 49(1):82-92.

25. DeYoung KL, Ray ME, Su YA, Anzick SL, Johnstone RW, Trapani JA, Meltzer PS, Trent JM: Cloning a novel member of the human interferon-inducible gene family associated with control of tumorigenicity in a model of human melanoma. Oncogene 1997, 15(4):453-457.

26. Ding Y, Wang L, Su LK, Frey JA, Shao R, Hunt KK, Yan DH: Antitumor activity of IFIX, a novel interferon-inducible HIN-200 gene, in breast cancer. Oncogene 2004, 23(26):4556-4566.

27. Ludlow LE, Hii LL, Thorpe J, Newbold A, Tainton KM, Trapani JA, Clarke CJ, Johnstone RW: Cloning and characterisation of Ifi206: a new murine HIN-200 family member. J Cell Biochem 2008, 103(4):1270-1282.

28. Zhang K, Kagan D, DuBois W, Robinson R, Bliskovsky V, Vass WC, Zhang S, Mock BA: Mndal, a new interferon-inducible family member, is highly polymorphic, suppresses cell growth, and may modify plasmacytoma susceptibility. Blood 2009, 114(14):2952-2960.
29. Keating SE, Baran M, Bowie AG: Cytosolic DNA sensors regulating type I interferon induction. Trends Immunol 2011, 32(12):574-581.

30. Schattgen SA, Fitzgerald KA: The PYHIN protein family as mediators of host defenses. Immunol Rev 2011, 243(1):109-118.

31. Li T, Diner BA, Chen J, Cristea IM: Acetylation modulates cellular distribution and DNA sensing ability of interferon-inducible protein IFI16. Proc Natl Acad Sci USA 2012, 109(26):10558-10563.

32. Liu C, Wang H, Zhao Z, Yu S, Lu YB, Meyer J, Chatterjee G, Deschamps S, Roe BA, Lengyel P: MyoD-dependent induction during myoblast differentiation of p204, a protein also inducible by interferon. Mol Cell Biol 2000, 20(18):7024-7036.

33. Chen IF, Ou-Yang F, Hung JY, Liu JC, Wang H, Wang SC, Hou MF, Hortobagyi GN, Hung MC: AIM2 suppresses human breast cancer cell proliferation in vitro and mammary tumor growth in a mouse model. Mol Cancer Ther 2006, 5(1):1-7.

34. Aglipay JA, Lee SW, Okada S, Fujiuchi N, Ohtsuka T, Kwak JC, Wang Y, Johnstone RW, Deng C, Qin J, Ouchi T: A member of the Pyrin family, IFI16, is a novel BRCA1-associated protein involved in the p53-mediated apoptosis pathway. Oncogene 2003, 22(55):8931-8938.

35. Dermott JM, Gooya JM, Asefa B, Weiler SR, Smith M, Keller JR: Inhibition of growth by p205: a nuclear protein and putative tumor suppressor expressed during myeloid cell differentiation. Stem Cells 2004, 22(5):832-848.

36. Lembo M, Sacchi C, Zappador C, Bellomo G, Gaboli M, Pandolfi PP, Gariglio M, Landolfo S: Inhibition of cell proliferation by the interferon-inducible 204 gene, a member of the Ifi 200 cluster. Oncogene 1998, 16(12):1543-1551.

37. Dauffy J, Mouchiroud G, Bourette RP: The interferon-inducible gene, Ifi204, is transcriptionally activated in response to M-CSF, and its expression favors macrophage differentiation in myeloid progenitor cells. J Leukoc Biol 2006, 79(1):173-183.

38. Xin H, Pereira-Smith OM, Choubey D: Role of IFI 16 in cellular senescence of human fibroblasts. Oncogene 2004, 23(37):6209-6217.

39. Luan Y, Lengyel P, Liu CJ: p204, a p200 family protein, as a multifunctional regulator of cell proliferation and differentiation. Cytokine Growth Factor Rev 2008, 19(5-6):357-369.

40. Asefa B, Klarmann KD, Copeland NG, Gilbert DJ, Jenkins NA, Keller JR: The interferon-inducible p200 family of proteins: a perspective on their roles in cell cycle regulation and differentiation. Blood Cells $\mathrm{Mol}$ Dis 2004, 32(1):155-167.

41. Choubey D, Panchanathan R: Interferon-inducible Ifi200-family genes in systemic lupus erythematosus. Immunol Lett 2008, 119(1-2):32-41.

42. Gariglio M, Mondini M, De Andrea M, Landolfo S: The multifaceted interferon-inducible p200 family proteins: from cell biology to human pathology. J Interferon Cytokine Res 2011, 31(1):159-172.

43. Hertel L, Rolle S, De Andrea M, Azzimonti B, Osello R, Gribaudo G, Gariglio M, Landolfo S: The retinoblastoma protein is an essential mediator that links the interferon-inducible 204 gene to cell-cycle regulation. Oncogene 2000, 19(32):3598-3608.

44. Asefa B, Dermott JM, Kaldis P, Stefanisko K, Garfinkel DJ, Keller JR: p205, a potential tumor suppressor, inhibits cell proliferation via multiple pathways of cell cycle regulation. FEBS Lett 2006, 580(5):1205-1214.

45. Choubey $D$, Lengyel P: Binding of an interferon-inducible protein (p202) to the retinoblastoma protein. J Biol Chem 1995, 270(11):6134-6140.

46. Liu CJ, Chang E, Yu J, Carlson CS, Prazak L, Yu XP, Ding B, Lengyel P, Di Cesare PE: The interferon-inducible p204 protein acts as a transcriptional coactivator of Cbfa1 and enhances osteoblast differentiation. J Biol Chem 2005, 280(4):2788-2796.

47. Wang H, Liu C, Lu Y, Chatterjee G, Ma XY, Eisenman RN, Lengyel P: The interferon- and differentiation-inducible p202a protein inhibits the transcriptional activity of c-Myc by blocking its association with Max. J Biol Chem 2000, 275(35):27377-27385.

48. Ding B, Lengyel P: p204 protein is a novel modulator of ras activity. J Biol Chem 2008, 283(9):5831-5848.

49. Choubey D, Gutterman JU: Inhibition of E2F-4/DP-1-stimulated transcription by p202. Oncogene 1997, 15(3):291-301.

50. Min W, Ghosh S, Lengyel P: The interferon-inducible $\mathrm{p} 202$ protein as a modulator of transcription: inhibition of NF-kappa B, c-Fos, and c-Jun activities. Mol Cell Biol 1996, 16(1):359-368. 
51. Fukushi M, Higuchi M, Oie M, Tetsuka T, Kasolo F, Ichiyama K, Yamamoto N, Katano H, Sata T, Fujii M: Latency-associated nuclear antigen of Kaposi's sarcoma-associated herpesvirus interacts with human myeloid cell nuclear differentiation antigen induced by interferon alpha. Virus Genes 2003, 27(3):237-247.

52. Xin H, D'Souza S, Fang L, Lengyel P, Choubey D: p202, an interferoninducible negative regulator of cell growth, is a target of the adenovirus E1A protein. Oncogene 2001, 20(47):6828-6839.

53. Cristea IM, Moorman NJ, Terhune SS, Cuevas CD, O'Keefe ES, Rout MP, Chait BT, Shenk T: Human cytomegalovirus pUL83 stimulates activity of the viral immediate-early promoter through its interaction with the cellular IFI16 protein. J Virol 2010, 84(15):7803-7814.

54. Park HH, Lo YC, Lin SC, Wang L, Yang JK, Wu H: The death domain superfamily in intracellular signaling of apoptosis and inflammation. Annu Rev Immunol 2007, 25:561-586.

55. Albrecht M, Choubey D, Lengauer T: The HIN domain of IFI-200 proteins consists of two OB folds. Biochem Biophys Res Commun 2005 327(3):679-687.

56. Jin $T$, Perry A, Jiang J, Smith P, Curry JA, Unterholzner L, Jiang Z, Horvath G Rathinam VA, Johnstone RW, Hornung V, Latz E, Bowie AG, Fitzgerald KA Xiao TS: Structures of the HIN domain:DNA complexes reveal ligand binding and activation mechanisms of the AIM2 inflammasome and IFI16 receptor. Immunity 2012, 36(4):561-571.

57. Liao JC, Lam R, Brazda V, Duan S, Ravichandran M, Ma J, Xiao T, Tempel W, Zuo X, Wang YX, Chirgadze NY, Arrowsmith CH: Interferon-inducible protein 16: insight into the interaction with tumor suppressor p53. Structure 2011, 19(3):418-429.

58. Brazda V, Coufal J, Liao JC, Arrowsmith CH: Preferential binding of IFI16 protein to cruciform structure and superhelical DNA. Biochem Biophys Res Commun 2012, 422(4):716-720.

59. Gribaudo G, Riera L, Hertel L, Landolfo $S$ : In vitro and in vivo expression analysis of the interferon-inducible 203 gene. J Interferon Cytokine Res 1999, 19(2):129-136.

60. Wang H, Chatterjee G, Meyer JJ, Liu CJ, Manjunath NA, Bray-Ward P, Lengyel P: Characteristics of three homologous 202 genes (Ifi202a, Ifi202b, and Ifi202c) from the murine interferon-activatable gene 200 cluster. Genomics 1999, 60(3):281-294.

61. Fernando MM, de Smith AJ, Coin L, Morris DL, Froguel P, Mangion J, Blakemore Al, Graham RR, Behrens TW, Vyse TJ: Investigation of the HIN200 locus in UK SLE families identifies novel copy number variants. Ann Hum Genet 2011, 75(3):383-397.

62. Tannenbaum CS, Major J, Ohmori Y, Hamilton TA: A lipopolysaccharideinducible macrophage gene (D3) is a new member of an interferoninducible gene cluster and is selectively expressed in mononuclear phagocytes. J Leukoc Biol 1993, 53(5):563-568

63. Zhang $Y$, Tian $Q, D u Y$, Cao H, Lengyel P, Kong W: Multiple splicing result in at least two p203 proteins that are expressed in the liver and downregulated during liver regeneration. Front Biosci 2008, 13:2444-2451.

64. Springer MS, Murphy WJ: Mammalian evolution and biomedicine: new views from phylogeny. Biol Rev Camb Philos Soc 2007, 82(3):375-392.

65. Prasad AB, Allard MW, Green ED: Confirming the phylogeny of mammals by use of large comparative sequence data sets. Mol Biol Evol 2008, 25(9):1795-1808.

66. Maetschke SR, Kassahn KS, Dunn JA, Han SP, Curley EZ, Stacey KJ, Ragan MA: $A$ visual framework for sequence analysis using $n$-grams and spectral rearrangement. Bioinformatics 2010, 26(6):737-744.

67. Meredith RW, Janecka JE, Gatesy J, Ryder OA, Fisher CA, Teeling EC, Goodbla A, Eizirik E, Simao TL, Stadler T, Rabosky DL, Honeycutt RL, Flynn JJ, Ingram CM, Steiner C, Williams TL, Robinson TJ, Burk-Herrick A, Westerman M, Ayoub NA, Springer MS, Murphy WJ: Impacts of the Cretaceous Terrestrial Revolution and $\mathrm{KPg}$ extinction on mammal diversification. Science 2011, 334(6055):521-524.

68. Gariglio M, Panico S, Cavallo G, Divaker C, Lengyel P, Landolfo S: Impaired transcription of the poly $\mathrm{rl}: \mathrm{rC}$ - and interferon-activatable 202 gene in mice and cell lines from the C57BL/6 strain. Virology 1992, 187(1):115-123.

69. Wei W, Clarke CJ, Somers GR, Cresswell KS, Loveland KA, Trapani JA, Johnstone RW: Expression of IFI 16 in epithelial cells and lymphoid tissues. Histochem Cell Biol 2003, 119(1):45-54.

70. Gariglio M, Azzimonti B, Pagano M, Palestro G, De Andrea M, Valente G, Voglino G, Navino L, Landolfo S: Immunohistochemical expression analysis of the human interferon-inducible gene IFI16, a member of the HIN200 family, not restricted to hematopoietic cells. J Interferon Cytokine Res 2002, 22(7):815-821.

71. Fujiuchi N, Aglipay JA, Ohtsuka T, Maehara N, Sahin F, Su GH, Lee SW, Ouchi T: Requirement of IFI16 for the maximal activation of p53 induced by ionizing radiation. J Biol Chem 2004, 279(19):20339-20344.

72. Rozzo SJ, Allard JD, Choubey D, Vyse TJ, Izui S, Peltz G, Kotzin BL: Evidence for an interferon-inducible gene, Ifi202, in the susceptibility to systemic lupus. Immunity 2001, 15(3):435-443.

73. Miranda RN, Briggs RC, Shults K, Kinney MC, Jensen RA, Cousar JB: Immunocytochemical analysis of MNDA in tissue sections and sorted normal bone marrow cells documents expression only in maturing normal and neoplastic myelomonocytic cells and a subset of normal and neoplastic B lymphocytes. Hum Pathol 1999, 30(9):1040-1049.

74. Wu C, Orozco C, Boyer J, Leglise M, Goodale J, Batalov S, Hodge CL, Haase J, Janes J, Huss JW 3rd, Su Al: BioGPS: an extensible and customizable portal for querying and organizing gene annotation resources. Genome Biol 2009, 10(11):R130.

75. Cordaux R, Batzer MA: The impact of retrotransposons on human genome evolution. Nat Rev Genet 2009, 10(10):691-703.

76. Stetson DB, Ko JS, Heidmann T, Medzhitov R: Trex1 prevents cell-intrinsic initiation of autoimmunity. Cell 2008, 134(4):587-598.

77. Belancio VP, Roy-Engel AM, Deininger PL: All y'all need to know 'bout retroelements in cancer. Semin Cancer Biol 2010, 20(4):200-210.

78. Lander ES, Linton LM, Birren B, Nusbaum C, Zody MC, Baldwin J, Devon K, Dewar K, Doyle M, FitzHugh W, Funke R, Gage D, Harris K, Heaford A, Howland J, Kann L, Lehoczky J, LeVine R, McEwan P, McKernan K, Meldrim J, Mesirov JP, Miranda C, Morris W, Naylor J, Raymond C, Rosetti M, Santos R, Sheridan A, Sougnez C, et al: Initial sequencing and analysis of the human genome. Nature 2001, 409(6822):860-921.

79. Bailey TL, Elkan C: Fitting a mixture model by expectation maximization to discover motifs in biopolymers. Proc Int Conf Intell Syst Mol Biol 1994, 2:28-36.

80. Bailey $\mathrm{TL}$, Gribskov M: Methods and statistics for combining motif match scores. J Comput Biol 1998, 5(2):211-221

81. Finn RD, Clements J, Eddy SR: HMMER web server: interactive sequence similarity searching. Nucleic Acids Res 2011, 39:W29-W37. Web Server issue.

82. Larkin MA, Blackshields G, Brown NP, Chenna R, McGettigan PA, McWilliam H, Valentin F, Wallace IM, Wilm A, Lopez R, Thompson JD, Gibson TJ, Higgins DG: Clustal W and Clustal X version 2.0. Bioinformatics 2007, 23(21):2947-2948

83. Goujon M, McWilliam H, Li W, Valentin F, Squizzato S, Paern J, Lopez R: A new bioinformatics analysis tools framework at EMBL-EBI. Nucleic Acids Res 2010, 38:W695-W699. Web Server issue.

84. Ronquist F, Huelsenbeck JP: MrBayes 3: Bayesian phylogenetic inference under mixed models. Bioinformatics 2003, 19(12):1572-1574.

85. Jones DT, Taylor WR, Thornton JM: The rapid generation of mutation data matrices from protein sequences. Comput Appl Biosci 1992, 8(3):275-282.

86. Maddison WP, Maddison DR: Mesquite: a modular system for evolutionary analysis. Version 2.6. 2011. http://mesquiteproject.org.

87. Guindon S, Dufayard JF, Lefort V, Anisimova M, Hordijk W, Gascuel O New algorithms and methods to estimate maximum-likelihood phylogenies: assessing the performance of PhyML 3.0. Syst Biol 2010 59(3):307-321

88. Le SQ, Gascuel O: An improved general amino acid replacement matrix. Mol Biol Evol 2008, 25(7):1307-1320.

89. Hordijk W, Gascuel O: Improving the efficiency of SPR moves in phylogenetic tree search methods based on maximum likelihood. Bioinformatics 2005, 21(24):4338-4347.

90. Anisimova M, Gascuel O: Approximate likelihood-ratio test for branches: A fast, accurate, and powerful alternative. Syst Biol 2006, 55(4):539-552

91. Costelloe EO, Stacey KJ, Antalis TM, Hume DA: Regulation of the plasminogen activator inhibitor-2 (PAl-2) gene in murine macrophages. Demonstration of a novel pattern of responsiveness to bacterial endotoxin. J Leukoc Biol 1999, 66(1):172-182.

92. Sester DP, Trieu A, Brion K, Schroder K, Ravasi T, Robinson JA, McDonald RC, Ripoll V, Wells CA, Suzuki H, Hayashizaki Y, Stacey KJ, Hume DA, Sweet MJ: LPS regulates a set of genes in primary murine macrophages by antagonising CSF-1 action. Immunobiology 2005, 210(2-4):97-107. 
93. Meadows NA, Sharma SM, Faulkner GJ, Ostrowski MC, Hume DA, Cassady Al: The expression of $\mathrm{Clcn} 7$ and Ostm 1 in osteoclasts is coregulated by microphthalmia transcription factor. J Biol Chem 2007, 282(3):1891-1904.

94. Pfaffl MW: A new mathematical model for relative quantification in real-time RT-PCR. Nucleic Acids Res 2001, 29(9):e45.

doi:10.1186/1471-2148-12-140

Cite this article as: Cridland et al.: The mammalian PYHIN gene family:

Phylogeny, evolution and expression. BMC Evolutionary Biology 2012

12:140.

\section{Submit your next manuscript to BioMed Central} and take full advantage of:

- Convenient online submission

- Thorough peer review

- No space constraints or color figure charges

- Immediate publication on acceptance

- Inclusion in PubMed, CAS, Scopus and Google Scholar

- Research which is freely available for redistribution 